\title{
Regulation and Business Behavior*
}

\author{
NEIL GUNNINGHAM and ROBERT A. KAGAN
}

If socio-legal research has taught us anything, it is that legal coercion is expensive and difficult. Law can rarely hope to be meaningful and effective without the cooperation, indeed the normative accord, of the vast majority of populations it hopes to control. Thus after years of researching the behavior of regulatory agencies, regulatory scholars increasingly have turned their attention to the principal subjects of regulation, business entities themselves. For while governments promulgate laws and regulations, it is business corporations that must test the safety of products and vehicles, devise ways of reducing workplace hazards, and institute accurate accounting systems. Environmental regulation depends almost entirely on business firms to develop, finance and install pollution measurement and prevention technologies. The day-to-day effectiveness of regulatory compliance measures depends on the training and diligence of the corporate employees assigned to maintain equipment, monitor quality-control systems, train operatives, and take appropriate action when problems occur.

For socio-legal scholars, therefore, the key theoretical and empirical issues have come to involve the relationships between regulatory norms and business behavior. What factors, legal and non-legal, influence the incidence of compliance and over-compliance? How do firms respond to different modes of regulation, and to different enforcement styles? What explains variation among enterprises in responsiveness to regulatory goals? How do variations in market structure and conditions affect business attitudes toward legal compliance? How do different modes of regulation affect business decision-making concerning innovation and investment?

One particularly salient set of issues, reflected in the several studies in this issue, concerns business motives to comply with (or evade) regulations. How important in bringing about compliance is the imminent threat of legal sanctions-as compared to education, social pressures, and internalized commitments to comply with law? Existing research points to a tension between (a) the common vision of business firms as "amoral calculators," motivated only by rational self-interest (Kagan \& Scholz 1984), and

\footnotetext{
* Address correspondence to Neil Gunningham, REGNET, University House, Australian National University, Canberra ACT 0200, Australia; e-mail: neil.gunningham@anu.edu.au 
(b) researchers' findings that in many regulatory contexts, legal compliance by business firms is more common than might be expected, given the level of formal enforcement and legal sanctions (Kagan \& Axelrad 2000; Mehta \& Hawkins 1998). Many firms, it appears, are not closely attentive to the actual incidence and risk of sanctions, and often compliance is not closely related to perceived risk of punishment for noncompliance (Braithwaite \& Makkai 1991). Moreover, there is considerable variation among firms in their response to similar regulatory standards, with some facilities-contrary to simple economic models-instituting compliance measures that go well beyond those required by legal rules (Gunningham, Kagan \& Thornton 2003; Kagan \& Axelrad 2000).

At the same time, most scholars believe that the threat of legal sanctions is essential to regulatory compliance, and some research supports this view (Harrison 1995; Scholz \& Gray 1990). Thus, before a reliable model of firms' behavior can be constructed, much remains to be learned about the relative importance of legal threat, social pressures, and internalized norms-under various legal, political, economic, and social conditions. And this requires answers to a series of more specific questions: How salient and important are the general deterrence messages of formal sanctions as stimuli for compliance efforts by regulated businesses, as compared to the stimuli of more intense monitoring and inspection? How tightly coupled are social pressures to formal legal rules and sanctions? That is, do formal rules, inspections, and sanctions trigger other pressures and motivations, or do other motivations arise independently? To what extent, and under what conditions, can informal pressures from industry associations and market forces substitute for formal rules and threats? To what extent do violations arise from ignorance, organizational overload, and confusion, as compared to economic calculation? Do corporate motivations and compliance rates vary predictably by size and profitability, or the characteristics of particular industry sectors?

The articles in this Special Issue contribute to our repository of empirical knowledge on these and related questions. They reflect innovative empirical research projects, creating new quantitative measures of behavioral responses to regulation by business firms. Collectively, they enrich our understanding of both specific and general deterrence, the puzzle of "overcompliance," the consequences of different modes of enforcement, and the reasons why different companies, even in the same sector, respond very differently to seemingly similar external pressures, and the circumstances under which "technologyforcing" regulation elicits the desired innovative business behavior.

The articles by John Mendeloff and Wayne Gray (2005), and by Wayne Gray and Ronald Shadbegian (2005) illuminate the role of specific deterrence (and inspections in particular) in shaping corporate behavior. To that end, Mendeloff and Gray seek to clarify the causal factors underlying the preventive actions that firms take. Building on their earlier work, they test different models of employers' responses to Occupational Safety and Health Administration (OSHA) inspections that levy penalties for violations. Those 
employer responses, they find, are not restricted to measures that focus exclusively on improved compliance with OSHA standards. Indeed, the largest impact of penalty inspections seems to flow from increases in managerial attention to safety in general-a finding that has important policy implications for targeting enforcement resources.

In a complementary article, Wayne Gray and Ronald Shadbegian (2005) examine differences in compliance with air pollution regulation at U.S. pulp and paper mills. Testing a variety of plant and firm-specific variables, as well as the frequency of enforcement activity, they conclude that regulatory inspections (specific deterrence) are associated with better compliance, as are some plant-level characteristics (type of manufacturing process, newer facilities, smaller facilities), while corporate-level characteristics are not significant determinants of compliance at plant level. Furthermore, plantlevel compliance rates, they find, are correlated across different regulatory programs - plants that violate water pollution and OSHA regulations are also more likely to be out of compliance with air pollution rules-which may point to the significance of plant-level management as an important variable (see also Gunningham, Kagan \& Thornton 2003).

For Dorothy Thornton, Neil Gunningham, and Robert Kagan (2005), the empirical focus is general deterrence, and with what they term "explicit general deterrence." Based on a survey of over 200 firms, they found that a majority had no recall of a significant penalty recently imposed on a firm in the respondent's own industry and state, and that neither knowledge of other penalty cases nor perceived risk of detection and fine was associated with self-reported improvements in compliance-related behavior. Nevertheless, general deterrence seems to have a cumulative effect on the consciousness of regulated companies. Deterrence signals both served to reassure "good apples" that violators will be punished and reminded firms to check their own compliance programs. Neil Gunningham, Dorothy Thornton, and Robert Kagan's companion article uses qualitative data to delve more deeply into regulated firms' perceptions of the role of general deterrence, specific deterrence, and other factors in motivating firms' environmental actions. A comparison of two different industry sectors suggested that of far greater importance than either specific or general deterrence was what they term "implicit general deterrence," where the outcome of sustained inspection and enforcement activity is to inculcate a "culture of compliance" in which it was the regulations themselves rather than enforcement action that had a direct impact on compliance behavior.

Peter May (2005) takes a broader approach, seeking to disentangle the interwoven factors that best explain the willingness to comply under varied circumstances. He focuses in particular on the relative significance of (a) the fear associated with being found in violation of regulatory requirements, as compared with (b) the sense of civic duty to comply. To do so, he draws upon three studies recently completed by himself and his colleagues: compliance by farmers in Denmark with agro-environmental regulations, 
compliance by residential contractors in Washington with building-code provisions, and actions taken by marine facilities in California and Washington to address potential harms to water quality. While he finds that specific deterrence, exemplified by regulatory inspections, does matter, their chief significance for most firms is in sharpening or actualizing an underlying propensity to voluntary compliance, for example, by educating firms about specific problems and compliance measures and assuring them that the law is enforced consistently against competitors.

Margaret Taylor, Edward Rubin, and David Hounshell (2005) address a somewhat different issue: how industry responds to governmental "actionforcing" regulations, in this case, federal rules that demanded large reductions in $\mathrm{SO}_{2}$ emissions from coal-fired power plants. To comply with those legal standards, considerable (and very expensive) technological innovation and investment was required. Simultaneously, the federal government sponsored and sought to disseminate research concerning technological approaches to the problem. Taylor, Rubin, and Hounshell find, based on studies of patenting activity, that government regulation stimulated invention more effectively than government-sponsored research support alone. Moreover, even the anticipation of regulation spurred inventive activity, as regulatory goals focused inventive activity in particular technical directions and stimulated markets for new environmental technologies. The authors also found that as regulation accelerated the use of more $\mathrm{SO}_{2}$ control technologies, operators learned better ways to run the systems, reducing the anticipated operating and capital costs of pollution reduction.

A number of papers in this volume also seek to explain variation in firm behavior. For example, Gray and Shadbegian find that plants differ in their responsiveness to enforcement activity and these differences are related to firm as well as to plant characteristics. Plants owned by larger firms were less responsive to inspections and more responsive to other enforcement actions. Gunningham, Thornton, and Kagan show that deterrence (general, specific, or implicit) was far more important to small and medium-sized enterprises than it was to large, reputation-sensitive corporations. Relatedly, large companies generally were proactive and innovative in seeking leastcost ways of mitigating the costs of regulatory compliance and identifying "win-win" outcomes, while small companies were almost entirely reactive and rarely took advantage of such opportunities. For the larger chemical companies in Gunningham, Thornton, and Kagan's sample, regulation and its enforcement played only a minor role, serving to provide "a baseline", which most firms chose to go substantially beyond for reasons related to their perceived need to protect their social license to operate. For them, maintaining the trust of local communities, avoiding the attention of environmental groups and preserving the company's reputation as an environmentally responsible entity were of far greater importance than regulatory pressures.

Overall, the articles in this issue demonstrate that business behavior vis-àvis regulatory law and enforcement is complex and multi-faceted, and not 
adequately captured by traditional economic models which assume that firms respond only to short-term economic incentives, including predicted costs of detection and punishment. In economically advanced democracies, firms are concerned about their reputations and legitimacy as well, and often are responsive to the norms underlying regulatory requirements. Several of the articles thus find that a key contribution of regulation is to trigger and direct managerial commitments-educating them about regulatory concerns and problems, stimulating proactive measures to review and improve previously established compliance programs, or the search for more cost-effective modes of achieving regulatory goals.

One implication of the articles is that unraveling the puzzle of corporate motivation vis-à-vis legal norms is of considerable practical as well as theoretical interest. Not least, the articles suggest means whereby regulators might refine their use of both specific and general deterrence, how they might target resources for better effect, how technology-forcing regulation can be used to encourage innovation, and how a range of other regulatory techniques can be invoked to shape business behavior.

\section{REFERENCES}

Braithwaite, J., and T. Makkai (1991) "Testing an Expected Utility Model of Corporate Deterrence," Law and Society Review 25: 7-40.

Gray, Wayne B., and Ronald J. Shadbegian (2005) "When and Why do Plants Comply? Paper Mills in the 1980s," Law \& Policy 27: 238-61.

Gunningham, N., R. Kagan, and D. Thornton (2003) Shades of Green: Business, Regulation, and Environment. Stanford, Calif: Stanford Univ. Press.

Gunningham, Neil A., Dorothy Thornton, and Robert A. Kagan (2005) "Motivating Management: Corporate Compliance in Environmental Protection," Law \& Policy 27: 289-316.

Harrison, Kathryn (1996) "Is Cooperation the Answer? Canadian Environmental Enforcement in Comparative Context," Journal of Policy Analysis \& Management 14: 221-34.

Kagan, R., and L. Axelrad (2000) Regulatory Encounters: Multinational Corporations and Adversarial Legalism. Berkeley: Univ. of California Press.

Kagan, R., and J. Scholz (1984) "The Criminology of the Corporation and Regulatory Enforcement Styles." In Enforcing Regulation, edited by K. Hawkins \& J. M. Thomas. Boston: Kluwer-Nijhoff.

Laplante, Benoit, and Paul Rilstone (1996) "Environmental Inspections and Emissions of the Pulp and Paper Industry in Quebec," Journal of Environmental Economics and Management 31: 19-36.

May, Peter J. (2005) "Compliance Motivations: Perspectives of Farmers, Homebuilders, and Marine Facilities," Law \& Policy 27: 317-47.

Mehta, A., and K. Hawkins (1998) "Integrated Pollution Control and its Impact," Journal of Environmental Law 10(1): 61-77.

Mendeloff, John, and Wayne B. Gray (2005) "Inside the Black Box: How Do OSHA Inspections Lead to Reductions in Workplace Injuries?" Law \& Policy 27: 219-37. 
Scholz, John T., and Wayne B. Gray (1990) "OSHA Enforcement and Workplace Injuries: A Behavioral Approach to Risk Assessment," Journal of Risk and Uncertainty 3: 283-305.

Taylor, Margaret R., Edward S. Rubin, and David A. Hounshell (2005) "Regulation as the Mother of Innovation: The Case of $\mathrm{SO}_{2}$ Control," Law \& Policy 27: 348-78.

Thornton, Dorothy, Neil A. Gunningham, and Robert A. Kagan (2005) "General

Deterrence and Corporate Environmental Behavior," Law \& Policy 27: 262-88. 